(>)

\title{
CON RORTY CONTRA RORTY: DE LA TOLERANCIA A LA SOLIDARIDAD
}

Gabriel Jiménez Peña 


\title{
CON RORTY CONTRA RORTY: DE LA TOLERANCIA A LA SOLIDARIDAD*
}

Resumen: En este artículo se sostienen dos ideas principales. Por un lado, se defiende, con el filósofo norteamericano Richard Rorty (I), que la tolerancia constituye una virtud moral que los miembros de una sociedad democrática deben poseer si ésta ha de perdurar. Pero, por otro, se sostendrá que (II) la mera tolerancia no es por sí misma suficiente y que la solidaridad es una virtud superior para que subsista la comunidad democrática liberal.

Palabras clave: Pragmatismo, solidaridad, tolerancia, Richard Rorty, sociedad democrática liberal.

\section{SINCE RORTY AGAINST RORTY: FROM TOLERANCE TO SOLIDARITY}

\begin{abstract}
In this paper I want two defend to principal ideas. In the first place, I will sustain, with Rorty, (I) tolerance is a moral virtue, which the members of a democratic society must have for it endures. In the second place (II), I will maintain, mere toleration is not enough by itself and a superior virtue, in order to liberal democratic community sustains or persists.
\end{abstract}

Keywords: Pragmatism, solidarity, tolerance, Richard Rorty, liberal democratic society.

Fecha de recepción: abril 23 de 2014

Fecha de aceptación: octubre 17 de 2014

Forma de citar: Jiménez, G. (2015). "Con Rorty contra Rorty: de la tolerancia a la solidaridad". Revista Filosofía UIS. 14 (1). pp. 45-53.

Gabriel Jiménez Peña: colombiano. Estudiante del doctorado en Ciencia Política, Universidad de los Andes y catedrático del Departamento de Ciencia Política de la misma universidad.

Correo electrónico: g.jimenez28@uniandes.edu.co

*Artículo de reflexión 


\section{CON RORTY CONTRA RORTY: DE LA TOLERANCIA A LA SOLIDARIDAD'}

"That imaginative realm of tolerance was born with modern Europe, it is the very image of Europe or at least our dream of Europe, a dream many times betrayed but nonetheless strong enough to unite us all in the fraternity that stretches far beyond the little European continent" ${ }^{\prime 2}$.

Milan Kundera, The Art of the Novel

Richard Rorty (1931-2007) constituye uno de los filósofos más provocadores y sugestivos de la época contemporánea, y de hecho, de acuerdo con el canon de $\mathrm{H}$. Bloom, el más interesante del mundo en los últimos tiempos (Voparil y Bernstein, 2010, p. 1). La obra de este filósofo pragmatista presenta dos caras: una crítica y otra propositiva. La parte crítica tiene que ver con el diagnóstico realizado sobre la filosofía moderna y la ilustración europea, en Filosofía y el espejo de la naturaleza (Rorty, 1979) y que arroja como resultado que éstas deben ser abandonadas o superadas. La parte propositiva consiste en un punto de vista acerca de la cultura, en particular, en torno de la ética y la política, una vez se abandonan los presupuestos modernos sobre los que se encuentra basada la filosofía, a saber, el representacionalismo, la teoría de la verdad como correspondencia y el fundacionalismo (Ramberg, 2009; Voparil y Bernstein, 2010).

\footnotetext{
${ }^{1}$ El autor agradece los comentarios del Profesor Christian Voparil, Profesor de Teoría política y filosofía del Union Institute University, Ohio. También agradece al lector anónimo del artículo por sus comentarios y sugerencias.

2 "Ese reino imaginativo de la tolerancia nació con la Europa moderna, es la imagen misma de Europa o, al menos, nuestro sueño de Europa, un sueño muchas veces traicionado, pero no obstante lo suficientemente fuerte como para unirnos a todos en la fraternidad que se extiende mucho más allá del pequeño continente europeo" Milan Kundera, El arte de la novela. Todas las traducciones son del autor de artículo.
} 
Este texto se concentra en la parte propositiva, es decir, en las publicaciones posteriores a la obra Filosofía y el espejo de la naturaleza, tales como Contingencia, Ironía y solidaridad (en adelante, CIS), Objetividad, relativismo y verdad (ORT), Achieving Our Country (AC), Philosophy and Social Hope (PSH) y Philosophy as Cultural Politics (PCP). En esta parte de su obra, el filósofo norteamericano, una vez arguye que no es posible aspirar a algo que se encuentre más allá de la historia y de las instituciones, es decir, bien que rechaza ideas tales como esencia, naturaleza y fundamento, acepta un liberalismo político post-metafísico, en tanto encarnado en una comunidad liberal contingente (Rorty, 1989).

(I) En el liberalismo político democrático, culturas con diferentes creencias y puntos de vista, han de convivir en sociedad y, por ello, han de aceptarse entre sí, a pesar de que diverjan en sus concepciones (Rawls, 1996)³. Dicha aceptación mutua, pese a las diferencias en puntos de vista es aquello que se entiende por tolerancia ${ }^{4}$. Ahora bien, de acuerdo con Rorty, el espíritu de la acomodación y tolerancia es "esencial para la democracia" (1991, p. 79). Más aún, sostiene Rorty, el sentido del valor moral de nuestra "cultura liberal burguesa" está fundado en su "tolerancia a la diversidad" (85). Y, en el párrafo quizás más revelador, de la importancia que tiene la tolerancia para la democracia liberal en su filosofía pragmatista, se encuentra el planteamiento reproducido a continuación:

Finalmente, nuestra especie ha estado creando una naturaleza para sí misma especialmente buena — la creada por las instituciones del Occidente liberal-. Cuando elogiamos esta realización, nosotros los pragmatistas desechamos la retórica revolucionaria de la emancipación y del desenmascaramiento a favor de la retórica reformista de una mayor tolerancia y menor sufrimiento (90).

\footnotetext{
${ }^{3}$ El liberalismo político consiste en el punto de vista que aboga por no ser una doctrina 'comprensiva', esto es, no busca ser ella misma una concepción de vida buena: una teoría general del valor, una teoría ética, una epistemología, o una metafísica controvertida sobre las personas o la sociedad. Las sociedades modernas, caracterizadas por un 'pluralismo razonable' están repletas ya de tales doctrinas. Por ello, el propósito del liberalismo político no es constituirse en otra doctrina sectaria, sino proporcionar un marco político neutral, entre dichas doctrinas comprensivas. Dado que busca, entonces, servir como base para el razonamiento público, el liberalismo político debe estar restringido a un núcleo esencial de principios políticos — los principios de justicia—, que son acordados a partir de un consenso traslapado (overlapping) por todos los ciudadanos razonables y que debe llevar a un equilibrio reflexivo entre las doctrinas comprensivas (Rawls, 1996, pp. 20-43).

4 “El término 'tolerancia' — del Latín tolerare: aguantar, consentir o sufrir—generalmente se refiere a la aceptación condicional de, o a la no interferencia con, las creencias, acciones y prácticas que se consideran equivocadas, pero todavía 'tolerables', de tal manera que no se deben prohibir o limitar" (Forst, 2012, p. 1). Es claro que hay otro sentido de tolerancia, y es el de 'resignarse no voluntariamente a sufrir un dolor', al cual no nos referiremos en este escrito. Para ver las entradas de este último sentido particular en la obra de Rorty, en relación con la crueldad (Rorty, 1989, p. 155; n. 166; 169).
} 
De lo anterior, se extrae, pues, que Rorty asume la tolerancia como el fundamento para la democracia. Esta idea, quizá provenga de la importancia que tenía ésta, en particular, en relación con la religión y la raza, en el pensamiento de Jefferson y Dewey, lo cual se puede ver claramente en la parte III de ORT: 'De la prioridad de la democracia sobre la Filosofía': "NOSOTROS — nosotros los modernos herederos de las tradiciones de tolerancia religiosa y el gobierno constitucional- ponemos la Libertad delante de la perfección" (Rorty, 1991, pp. 78-79).

Ahora bien, de acuerdo con Gutiérrez (2003), la idea de tolerancia liberal, que acoge Rorty, no es compatible por sí misma con la idea de una cultura democrática, pues:

Encubre la realidad de la dominación y de la asimetría, la desigualdad de los excluidos por cuya supuesta y abstracta igual dignidad individual se ha pagado el precio abrumador de la ceguera a sus diferencias. En la realidad liberal sólo es digno quien por encima de las diferencias comparte los valores de la tradición liberal; para ser cabalmente reconocidos como seres humanos, los otros tienen que ser despojados de todos los atributos concretos, personales e históricos que conforman la existencia humana. La tolerancia que se alza sobre semejantes cimientos es auto-destructiva porque impone la pérdida del hombre real asumiendo que el hombre nouménico como tal sea capaz de fundar una comunidad (69-70).

Con todo, se sostiene que la idea de tolerancia de Rorty sale bien librada de esta crítica, de la que, quizá Rawls, por contraste, no sale bien librado (Sandel, 1995). De hecho, es en el etnocentrismo, producido por la aculturación, donde tiene lugar una forma de ceguera respecto de las diferencias y que es un punto que reconocería Rorty a los comunitaristas como Gutiérrez. Por ello,

Nuestra mejor oportunidad para trascender nuestra aculturación es ser educado en una cultura que se enorgullezca de no ser monolítica — de su tolerancia a la pluralidad de subculturas y de su disposición a escuchar a las culturas vecinas- (Rorty, 1991, p. 9).

De ese modo, el punto interesante del Liberalismo 'ironista' rortyano, es que justamente no es ciego a la diferencia, como sí lo pueden ser otros liberalismos.

Ahora bien, la estrategia empleada para defender al filósofo pragmatista de esta crítica al concepto de tolerancia, y que él asume, consiste en tomar su argumentación expuesta en la parte I, capítulo de ORT: 'solidaridad u objetividad'. Allí Rorty sostiene que es cuando se busca fundamentar una virtud moral, en la objetividad, es decir, cuando se busca que, por ejemplo, la tolerancia sea universal, entonces se producen los problemas señalados por los comunitaristas (Sandel, 1995). 
Rorty proporciona, ciertamente, a la luz de 'Solidaridad u objetividad', una explicación procedimental de la tolerancia, antes que una substantiva (Miller, 2003, p. 101), esto es, su explicación supone no buscar fuentes trascendentes tales como el sujeto nouménico kantiano, Dios, la naturaleza humana, propiedades morales objetivas, teorías de la verdad y de la racionalidad, o en el caso de Rawls, el hombre ahistórico y sin cualidades de la posición original, sino, más bien, sospechar de las teorías que despojan a los hombres de sus atributos, de su historia y de su contingencia. En esa medida, debemos buscar las virtudes que mejor expresan, en tanto comunidad liberal burguesa postmoderna no universal, nuestros sentimientos morales contingentes y, así, proyectar nuestros estándares y criterios morales de tolerancia hacia el mundo.

De esa manera, surge la cuestión de si Rorty defiende, entonces, una suerte de 'dualismo tolerante', antes que un 'monismo tolerante'. Por un lado, se afirma que Rorty no defiende una posición según la cual deban ser tratados con tolerancia todos aquellos que acogen doctrinas comprensivas divergentes, con independencia del contenido de ésta (102). Más bien, dependiendo del contenido de la doctrina comprensiva, unas comunidades serán tratadas de modo tolerante, mientras otras no. De hecho, de acuerdo con Rorty, la justificación de la tolerancia es circular, por decirlo en sus palabras, etnocéntrica, pues toma la forma de una comparación entre sociedades que ejemplifican este hábito y aquellas que no, llevando a que una sociedad que ha experimentado las dos, es decir, la tolerancia y la intolerancia, prefiera la primera (Rorty, 1991, p. 16). En esa medida, la justificación de la tolerancia para Rorty, asume la misma forma de la justificación de la democracia para Churchill: "La democracia es la peor forma de gobierno, excepto por todas las otras demás formas que han sido probadas de tiempo en tiempo" (Churchill, 1947, p. 207). La tolerancia sería, pues, la peor actitud moral hacia otros seres humanos, excepto por todas las otras actitudes, tales como la intolerancia o la discriminación.

Por otro lado, y en el mismo orden de ideas, Rorty no sería un dualista tolerante, sino un monista tolerante, en la medida en que su ironismo liberal resulta tolerante con las formas de discriminación no liberales, a saber, con el racismo, la violencia y la inequidad de género y la injusticia: "su celebración de un nuevo goce tolerante de múltiples juegos de lenguaje y vocabularios es poco más que una apología ideológica de una versión antigua del liberalismo de la guerra fría que se puso el ropaje para del discurso de moda 'post-moderno'. Este consiste sin duda en dar un paso adelante, dos pasos hacia atrás" (Voparil y Bernstein, 2010, p. 556). Más aún, de acuerdo con el mismo Rorty:

Cuando los liberales burgueses empezamos a pensar de este modo — cuando, por ejemplo, reaccionamos a los Nazis y a los fundamentalistas con indignación y desprecio- tenemos que pensarlo dos veces. Pues estamos ejemplificando la actitud que afirmamos detestar. Preferiríamos morir a ser etnocéntricos, pero 


\begin{abstract}
el etnocentrismo es precisamente la convicción de que preferiríamos morir antes que compartir determinadas creencias. Entonces nos preguntamos si nuestro propio liberalismo burgués no es solo un ejemplo más de sesgo cultural. Semejante desconcierto nos deja expuestos a la sugerencia de que la cultura de la democracia liberal occidental está de algún modo 'en pie de igualdad' con la de los vándalos y la de los $l k$. Empezamos de ese modo a preguntarnos si nuestros intentos por hacer que otras partes del mundo adopten nuestra cultura son de diferente especie de los esfuerzos que los misioneros fundamentalistas. Si seguimos demasiado lejos esta línea de pensamiento, llegamos a ser lo que en ocasiones se denomina liberales 'húmedos'. Empezamos a perder capacidad de indignación moral, capacidad de sentir desprecio. Se disuelve nuestro sentido de identidad. Ya no podemos sentir orgullo por ser liberales burgueses, por formar parte de una gran tradición, ciudadanos de una cultura nada mediocre. Hemos llegado a tener una mente tan abierta que se nos ha salido el cerebro (Rorty, 1991, p. 203).
\end{abstract}

Es decir, en el pensamiento de Rorty hay una tensión no resuelta, entre 'no tolerar lo intolerable', y 'tolerar lo intolerable', conducente a que el concepto de tolerancia sea aceptado sólo como puerta de entrada para un concepto más importante en su obra, a saber: el de solidaridad. Esto implica, entonces, hacer una crítica más radical que la de Gutiérrez (2003) respecto del concepto de tolerancia.

(II) La tolerancia, como Bernard Williams observó una vez, es una 'virtud imposible' (Williams, 1996, p. 18). Es imposible porque implica la aceptación o el acatamiento o la acomodación a puntos de vista que, para algunos, en nuestro caso en tanto liberales ironistas, constituyen opciones de vida soportables a secas, de lejos: abyectas, como por ejemplo, el racismo, la violencia contra la mujer y la discriminación social. Lo abyecto en palabras de I. M. Young:

Es un sentimiento de aversión y repugnancia que el sujeto tiene al enfrentarse con ciertas cuestiones, imágenes y fantasías, lo horrible, respecto de lo cual solo puede responder con aversión, con náusea y con rechazo. Lo abyecto es al mismo tiempo fascinante; tira del sujeto para repelerlo. Lo abyecto es algo sin sentido, repulsivo de un modo irracional, no representable (1990, p. 241).

Esto significa, pues, que la tolerancia es un concepto normativamente dependiente (Forst, 2012). Ello quiere decir que, por sí mismo, éste no puede proveer razones substantivas para la objeción, la aceptación y el rechazo. Por consiguiente, la tolerancia necesita fuentes independientes en orden a tener cierta substancia, contenido y límites, y en orden a ser considerada como buena para una sociedad democrática. En sí misma, la tolerancia no es una virtud o un valor; porque, puede ser considerada como tal si es puesta en relación con otras razones normativas. Ello explica la tensión al interior del pensamiento de Rorty; pero, 
también es necesario ponerla en relación con la solidaridad, como un concepto normativo, a fin de no quedarnos sin herramientas para enfrentar al racista o al discriminador sexual.

En última instancia, el argumento esgrimido aquí con el objetivo de no considerar a la tolerancia como buena por sí misma para una democracia, es decir, sin que esté complementada por la solidaridad, se plantea del siguiente modo: por un lado, demasiada tolerancia hacia la violencia y hacia el mal, puede llevar a una indiferencia hacia dolor humano y la crueldad, que, a su vez, da lugar a una triste resignación que termina por legitimar esas formas de comportamiento. Por ejemplo, podemos decir que las probabilidades de que un judío en la época de Auschwitz fuera ayudado por sus vecinos eran menores si éste vivía en Bélgica, que si éste vivía en Dinamarca o Italia (Rorty, 1989, p. 189), justamente porque la sociedad belga era más tolerante al nazismo; aunque, igualmente, tolerantes con los judíos, y no solidarios, como los daneses o los italianos. Por otra parte, y de manera más importante, un judío o un afrodescendiente o una mujer discriminada, y en general, un marginado, prefiere siempre recibir solidaridad a recibir tolerancia. Esto es algo a favor de lo cual, se afirma siguiendo a Rorty, sólo se puede dar una justificación circular:

Deberíamos tener en la mira a los marginados: personas que instintivamente concebimos aún como 'ellos' y no como 'nosotros'. Deberíamos intentar advertir nuestras similitudes con ellos. La forma correcta de analizar el lema ('tenemos obligaciones para con los seres humanos simplemente como tales') consiste en proponernos crear un sentimiento de solidaridad más amplio que el que tenemos ahora (196).

Entonces, es la solidaridad, en tanto una meta a alcanzar, una utopía, y no la tolerancia, la manera en que nosotros, quienes vivimos en una comunidad liberal, por medio de la imaginación, vemos a los extraños como compañeros en el sufrimiento. Con la tolerancia, ni necesitamos de la imaginación, ni nos importa su sufrimiento. De ese modo, mientras la solidaridad se crea incrementando nuestra sensibilidad a los detalles particulares del dolor y de la humillación de seres humanos distintos, desconocidos para nosotros (Rorty, 1989, pp. XVI), con la tolerancia, a secas, permanecerán los otros, con su sufrimiento aparte y como desconocidos que no merecen ser acompañados en su dolor $\Phi$

\section{REFERENCIAS}

Gutiérrez, C. (2003). "Cultura de conflictos en vez de tolerancia". Revista de estudios sociales. No. 14. pp. 63-70.

Miller, C. B. (2003). "Rorty and Tolerance". Theoria: A Journal Of Social \& Political Theory, (101), 94. pp. 94-108. 
Rawls, J. (1996). Political Liberalism. New York: Columbia University Press.

Rorty, R. (1979). Philosophy and the Mirror of Nature. Princeton: Princeton University Press.

Rorty, R. (1989). Contingency, Irony and Solidarity. Cambridge: Cambridge University Press [CIS].

Rorty, R. (1991). Objectivity, Relativism and Truth. Cambridge: Cambridge University Press.

Sandel, M. J., (1995), "Moral Argument and Liberal Toleration: Abortion and Homosexuality". En: Amitai Etzioni (Ed.), New Communitarian Thinking: Persons, Virtues, Institutions, and Communities. Charlottesville: University Press of Virginia.

Voparil, C. y Bernstein, R. (eds.). (2010). The Rorty Reader. Malden, M.A.: WileyBlackwell. pp. 456-462.

Young, I. M. (1990). Justice and the Politics of Difference. Princeton: Princeton University Press.

Williams, B. (1996). Toleration: an impossible virtue. Harvard: Harvard University Press.

\section{CIBERGRAFÍA}

Churchill, W. (1947). Discourse from a House of Commons speech on Nov. 11. London: House of commons. Parlamient Bill. Disponible en: http://hansard. millbanksystems.com/commons/1947/nov/11/parliament-bill

Forst, R. (2012)."Toleration". The Stanford Encyclopedia of Philosophy (Summer 2012 Edition). Zalta, E. (ed.) Recuperado de: http://plato.stanford.edu/archives/ sum2012/entries/toleration/

Ramberg, B. (2009). "Richard Rorty". The Stanford Encyclopedia of Philosophy (Spring 2009 Edition), Edward N. Zalta (ed.), URL = <http://plato.stanford.edu/ archives/spr2009/entries/rorty/> 